\title{
Dependence of new environmental nano organic semiconductor nickel-(II)-tetraphenyl-21H,23H-porphyrin films on substrate type for energy storage applications
}

\author{
A. El-Denglawey ${ }^{1,2} \cdot$ H. A. Alburaih ${ }^{3} \cdot$ M. M. Mostafa $^{4,5} \cdot$ M. S. Adam ${ }^{6,7} \cdot$ M. Dongol $^{2} \cdot$ M. M. El-Nahass $^{8} \cdot$ M. T. Alotaibi $^{9}$. \\ M. M. Makhlouf ${ }^{4}$
}

Received: 15 April 2020 / Revised: 4 June 2020 / Accepted: 29 June 2020 / Published online: 10 July 2020

(c) Islamic Azad University (IAU) 2020

\begin{abstract}
Characterization of organic nickel-(II)-tetraphenyl-21H,23H-porphyrin films as a function of substrate type was performed for energy storage applications and consequently environmental enhancement. Nickel-(II)-tetraphenyl-21H,23H-porphyrin films show an amorphous phase. They have a crystallite size of 8-11 nm. Strain caused a shift of different humps' positions. The measured transmittance has high values within the range of $85-91 \%$, and the absorption coefficient values were included within the high-absorption region. Both optical gap and fundamental gap, refractive index, carrier-concentrationto-effective-mass ratio and lattice dielectric constant were calculated, and they were found to be increased, except refractive index and lattice dielectric constant. The obtained data indicated that nickel-(II)-tetraphenyl-21H,23H-porphyrin films are a candidate for energy storage applications.
\end{abstract}

Keywords Energy storage $\cdot$ Environmental materials $\cdot$ Photovoltaic systems $\cdot$ Energy conversion $\cdot$ Nanomaterials $\cdot$ Thin films $\cdot$ Structural properties and optical properties

\section{Introduction}

Editorial responsibility: Fatih ŞEN.

A. El-Denglawey

denglawey@yahoo.com

1 Phys. Dept., Univ. College Fac., Taif University, Turabah 21995, Saudi Arabia

2 Nano \& Thin Film Lab., Phys. Dept., Fac. Sci., South Valley Univ., Qena 83523, Egypt

3 Phys. Dept., Fac. Sci., Princess Nourah Bint Abdulrahman University, Riyadh, Kingdom of Saudi Arabia

4 Phys. Dept., Univ. College Fac., Taif University, Raniah, Kingdom of Saudi Arabia

5 Phys. Dept., Fac. Sci., Suez University, Suez, Egypt

6 Chem. Dept., Fac. Sci., King Faisal University, 380 Al Hofuf, Al Hassa 31982, Kingdom of Saudi Arabia

7 Chem. Dept., Fac. Sci., Sohag University, Sohag 82534, Egypt

8 Phys. Dept., Fac. Educ., Ain Shams University, Cairo, Egypt

9 Chem. Dept., Univ. College Fac., Taif University, Turabah 21995, Kingdom of Saudi Arabia
Electrical energy has been used in environment, transportation such as planes, ships, fuel cars (Cuce et al. 2016), electrical cars and metro, heating, cooling and freezing of drugs and foods (Said and Hassan 2018), factories, air conditioner, home devices and instruments, different lightening processes, office requirements, laptops, PCs, etc. (Bode et al. 2003; Ratniyomchai and Kulworawanichpong 2017; Zhang et al. 2016).

Energy problems: storage, conversion and saving, have renewed much attention, especially nowadays due to COVID-19 pandemic (Steffen et al. 2020).

Due to COVID-19 pandemic, the demand on energy as well as energy consumption reached maximum because of people health strategies including isolation and quarantine which lead to high electricity consumption in homes, hospitals, medical factories, laboratory researches, etc. So it is necessary to introduce and enhance energy storage, conversion and saving processes to be used at normal or at peak and emergency times (Xu et al. 2019).

Due to the above context, there is a high demand for different energy types and resources which are depleted and/or 
renewable to enhance energy storage and clean environment (Alptekin et al. 2020). Fuel and/or traditional energy sources cause much environmental pollution, so new researches are needed to focus on clean energy and enhance the energy storage to avoid environmental pollution (Sen et al. 2017; Alptekin et al. 2020) and save emergency energy; in many cases, energy problems occur and emergency resources are needed instantly and immediately at peak consumption at night or day. In fact, the reality says "there is a huge difference between what is available and what is required" (Warren and Becken 2017; Al-Kuhaili 2019). So, there is a bad need for new methods to develop process of energy storage, saving and conversion.

There are many ideas to overcome energy problems (Sugiyama et al. 2016) such as using high-efficiency solar cells, high-capacity batteries or capacitors having long life and steady output (Xu et al. 2019), low-resistive materials, vibration energy-hydraulic energy conversion (He et al. 2020), highly conductive material, sensor control, lighting sources, phase change materials (PCMs), transparent heat mirror (THM) (Al-Kuhaili 2019; Said and Hassan 2018) and highdielectric materials such as ferroelectric and anti-ferroelectric materials which are good candidates for materials with higher energy storage density (Zhang et al. 2016), widening construction of nearly zero energy building (Favoino et al. 2015) and reduction in greenhouse gas emission (Wengenmayr and Bührke 2013).

Energy storage materials have been widely used, because of their advantages such as having high energy storage density, high efficiency, low energy and absorption loss (Ma et al. 2017; Zhang et al. 2016), high transmittance, optimum band gap and large absorption coefficient of $10^{4} \mathrm{~cm}^{-1}$ in the light visible range for high-efficiency solar cell (Zheng et al. 2018). In case of building energy storage, high-reflectance materials or window glass functional coatings, WGFC can be used as solar control and has low infrared emissivity coatings when climate becomes hot or cold to save energy (Zhang et al. 2018), etc., which consequently leads to more energy storage and energy saving.

Surface, temperature and type of substrate are the most important parameters that can affect the properties and the growth density of thin films in different devices for various industrial applications, especially in energy applications: saving, generation and storage, which finally have a positive effect on environmental enhancement and pollution reduction.

Many types of substrates are available. Solid substrates include conducting and non-conducting substrates (Hasani et al. 2019). Conducting substrates include transparent conducting oxide (TCO) substrates such as indium tin oxides (ITO), fluorine-doped tin oxide (FTO) and zinc oxide $(\mathrm{ZnO})$ and metal substrates such as $\mathrm{Ag}, \mathrm{Au}$ and $\mathrm{Si}$ (Kabir et al. 2019). Non-conducting substrates include amorphous substrate (glass), crystalline substrate (quartz) and flexible substrate (mica). Substrate can be used as a thin-film supporter or as a current collector in different energy applications (Ngamsinlapasathian et al. 2006; Hasani et al. 2019; Kabir et al. 2019).

Porphyrin compounds (PCs) have metal addition flexibility and are considered as a promise candidate for mass energy storage applications such as organic and lithium batteries, high execution energy storage devices, light energy conversion, electrochemical energy storage devices and organic solar cell (Karger et al. 2019; El-Denglawey et al. 2015; Kumar et al. 2017).

Bearing in mind the aforementioned context, nickel-(II)tetraphenyl-21H,23H-porphyrin (NiTPP) compound has drawn much attention due to its importance and interesting properties and large-scale energy storage applications such as being recycled, environmentally friendly, low-cost budget, high capacity, electronic conjugated system (18 $\pi$ electrons), high energy density and high conductive energy (Chen et al. 2019; Gao et al. 2017; El-Denglawey 2018; Makhlouf et al. 2014). Other details about advantages and properties of NiTPP are available in El-Denglawey (2018), Makhlouf et al. (2014) and El-Denglawey et al. (2015).

So, the aim of this work is focusing on the effect of substrate type on the spectrometric properties of NiTPP film organic semiconductor material as a good candidate for energy storage applications.

\section{Materials and methods}

NiTPP powder with $6 \mathrm{~N}$ purity was obtained from SigmaAldrich Company and heated in a quartz crucible using a tungsten coil under a vacuum of $10^{-6}$ torr and $0.5 \mathrm{~nm} \mathrm{~s}^{-1}$ constant evaporation rate using a vacuum coating unit (Edwards type E306A, England) to prepare $240 \mathrm{~nm}$ of NiTPP films on mica, glass and quartz substrates at room temperature and identical condition of time, thickness, crucible holder distance and pressure. From the reusability and durability view point, it is worth to mention that mica, glass and quartz substrates are hard enough and can be recycled or reused. Also, NiTPP films can be solved in DMF and can be redeposited.

Structural properties were characterized by X-ray diffraction technique using an XRD Philips diffractometer (type1710) with $\mathrm{CuK}_{\alpha}$ radiation $(\lambda=1.5406 \AA)$. XRD patterns were run at $40 \mathrm{kV}$ and $30 \mathrm{~mA}$ with a scanning speed of $3.761 \mathrm{~min}^{-1}$ at room temperature. Scherrer's equation is used to calculate the crystallite size of NiTPP films deposited on different substrates according to the following equation (Williamson and Hall 1953; El-Nahass et al. 2016; Dongol et al. 2015; Soliman et al. 2015): 
$D=\frac{K \lambda}{\beta \cos \theta}$

where $K$ is the constant having a value of $1, \beta$ represents the peak's full width half maximum (FWHM) in radians and $\lambda$ is the wavelength of $\mathrm{X}$-ray $\left(\mathrm{CuK}_{\alpha}\right.$ radiation equal to $1.54056 \AA$ ).

Optical properties were studied using spectrometric method; transmittance, $T$, and reflectance, $R$, were measured using a computerized Shimadzu UV-2100 doublebeam UVVIS scanning spectrophotometer at normal incidence within the wavelength range, $\lambda$, of 200-1100 $\mathrm{nm}$ of steps $10 \mathrm{~nm}$. Film thickness and evaporation rate were checked by a quartz crystal monitor FTM5 that was attached with the coating unit (El-Denglawey 2018; Dongol et al. 2004, 2016).

Both $T$ and $R$ are used to calculate optical constants and dispersion parameters: absorption coefficient, $\alpha$, optical gap, $E_{\mathrm{g}}^{\mathrm{opt}}$, and extinction coefficient, $k$, according to the following sequences (Tauc 1976; El-Denglawey 2018):

$T=(1-R)^{2} e^{-\alpha d}$

where $\alpha$ can be deduced and used to calculate $k$ :

$\alpha=\frac{1}{d} \ln \frac{(1-R)^{2}}{T}$

$k=\frac{\alpha \lambda}{4 \pi}$.

Finally, $E_{\mathrm{g}}^{\text {opt }}$ can be calculated according to the Tauc relation (Tauc 1976; El-Denglawey 2018):

$(\alpha h v)=A\left(h v-E_{\mathrm{g}}^{\mathrm{opt}}\right)^{r}$

where $A$ is the disordered function parameter representing the material's quality.

$A=4 \pi \sigma_{\min } / n c \Delta E_{\text {tail }}$

where $r$ is the index having different values $(1 / 2,3 / 2,2,3)$ and gives details about the available electronic transition, and additional details are available at Tauc (1976) and ElDenglawey et al. (2016).

Here, $\sigma_{\min }$ is the metallic conductivity, $c$ is the light velocity, and $\Delta E_{\text {tail }}=\Delta E_{\mathrm{c}}-\Delta E_{\mathrm{v}}$ gives the tailing broadening (ElDenglawey 2018; Tauc 1976).

The obtained data coincide with the indirect transition, $r=2$.

$(\alpha h v)=A\left(h v-E_{\mathrm{g}}^{\mathrm{opt}}\right)^{2}$.

Carrier-concentration-to-effective-mass ratio, $\mathrm{N} / \mathrm{m}^{*}$, and lattice dielectric constant, $\varepsilon_{\mathrm{L}}$, can be calculated from the intercept $\left(\lambda^{2}=0\right)$ and the slope of the graph according to the following equations (Wemple and DiDomenico 1970; El-Denglawey 2018):

$n=\left(\frac{1+R}{1-R}\right)$,

$n^{2}=\varepsilon_{\mathrm{L}}-\left(\frac{e^{2}}{4 \pi^{2} \varepsilon_{\mathrm{o}} c^{2}}\right)\left(\frac{\mathrm{N}}{\mathrm{m}^{*}}\right) \lambda^{2}$,

where $e$ represents the traditional elementary charge.

Dispersion energy, $E_{\mathrm{d}}$, oscillator energy, $E_{\mathrm{o}}$, and high-frequency dielectric constant, $\varepsilon_{\infty}$, can be calculated according to the following equation (Wemple and DiDomenico 1970: El-Denglawey 2011):

$\left(n^{2}(h v)-1\right)^{-1}=-\frac{1}{E_{\mathrm{o}} E_{\mathrm{d}}}(h v)^{2}+\frac{E_{\mathrm{o}}}{E_{\mathrm{d}}}$.

Values of $E_{\mathrm{d}}$ can be used to calculate constant $\beta$ which decides whether the compound is covalent or ionic according to the following equation (Tanaka 1980):

$E_{\mathrm{d}}=\gamma N_{\mathrm{c}} Z_{\mathrm{a}} N_{\mathrm{e}}(\mathrm{eV})$.

Constant $\gamma$ has two values: $0.377 \pm 0.05$ and $0.267 \pm 0.04 \mathrm{eV}$ which belong to covalent and ionic compounds, respectively, and $N_{\mathrm{c}}, Z_{\mathrm{a}}$ and $N_{\mathrm{e}}$ are cation coordination number of nearest neighbor, the anion formal chemical valence and the effective number of the valence electrons per anion, respectively. Dielectric properties were studied using the real, $\varepsilon_{1}$, and imaginary, $\varepsilon_{2}$, parts of the dielectric constant, $\varepsilon$ according to the following equations (Wemple and DiDomenico 1970; El-Denglawey 2018):

$\varepsilon_{1}=n^{2}-k^{2}$,

$\varepsilon_{2}=2 n k$,

$\varepsilon=\varepsilon_{1}-i \varepsilon_{2}$.

\section{Results and discussion}

\section{Structural properties}

The obtained XRD of NiTPP thin films on different substrates shows three humps of different widening and intensities as depicted in Fig. 1a-c. The presence of humps with different FWHMs and intensities gives information about internal structure. It was found that FWHMs decrease when intensities have opposite trend; such issue confirms the well formation of crystallite size with an increase in size (Osuwa and Chigbo 2012); FWHM of hump observed for NiTPP films deposited on mica substrate is the widest, decreases 


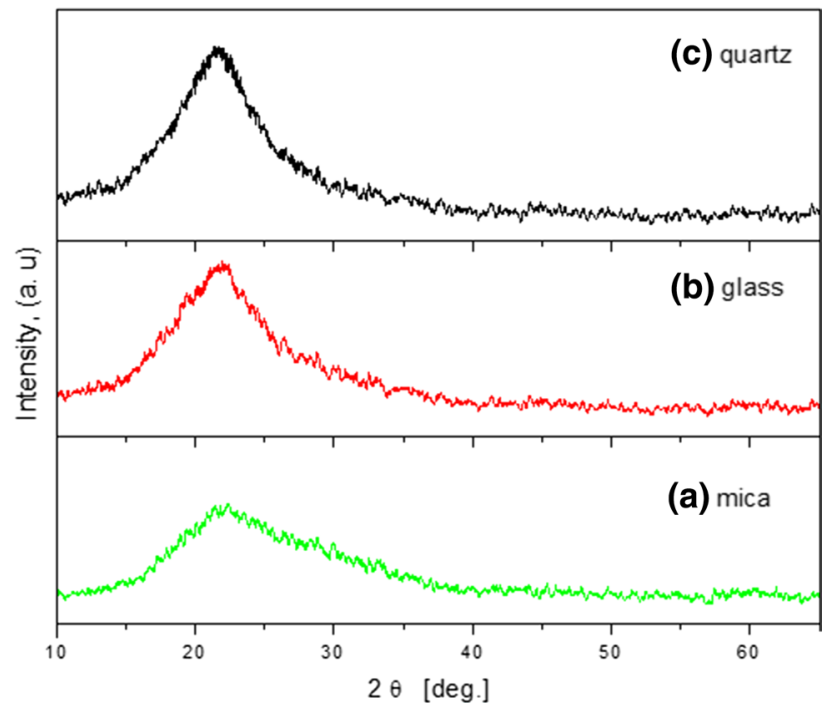

Fig. 1 XRD of NiTPP films on different substrates

in case of NiTPP films on glass substrate and is the smallest one in case of NiTPP films on quartz substrate, and the similar behavior was observed elsewhere (Hasani et al. 2019).

Higher values of FWHM mean that NiTPP films deposited on mica substrate have a higher disordered structure and more ordered structure in case of films deposited on glass and quartz substrates, respectively. One can observe that hump has different positions (Singh et al. 2014; Hasani et al. 2019). NiTPP films deposited on different substrates show that films have a variety of short-range order (SRO) characterized by a nanoscale crystallite size (Dongol et al. 2016). The calculated crystallite sizes of NiTPP films deposited on mica, glass and quartz substrates are 8,10 and $11 \mathrm{~nm}$, respectively. The released hump of NiTPP films on different substrates was attributed to amorphous phase because of disorder, while the shift of hump's position was attributed to microstrain (Singh et al. 2014; Dongol et al. 2016).

\section{Optical properties}

Optical characterization of NiTPP was studied by analyzing the features of both $T$ and $R$ as shown in Fig. 2. $T$ of NiTPP films is characterized by high values within the range between $85 \%$ for mica substrate and $91 \%$ for quartz substrate, and the maximum value of $R$ belongs to NiTPP films on mica substrate.

Two regions are characterizing $T$ curves. The first region at $\lambda=400-800 \mathrm{~nm}$ wavelength corresponds to the absorption region, and $\alpha, E_{\mathrm{g}}^{\mathrm{opt}}$ and $k$ can be calculated.

The other region at $\lambda>800 \mathrm{~nm}$ wavelength corresponds to the non-absorption region where the NiTPP films are transparent and dispersion parameters such as $n, E_{\mathrm{o}} E_{\mathrm{d}}, \varepsilon_{\mathrm{L}}, \varepsilon_{\infty}$ and $\mathrm{N} / \mathrm{m}^{*}$ can be calculated. At 435 and $500 \mathrm{~nm}, T$ shows

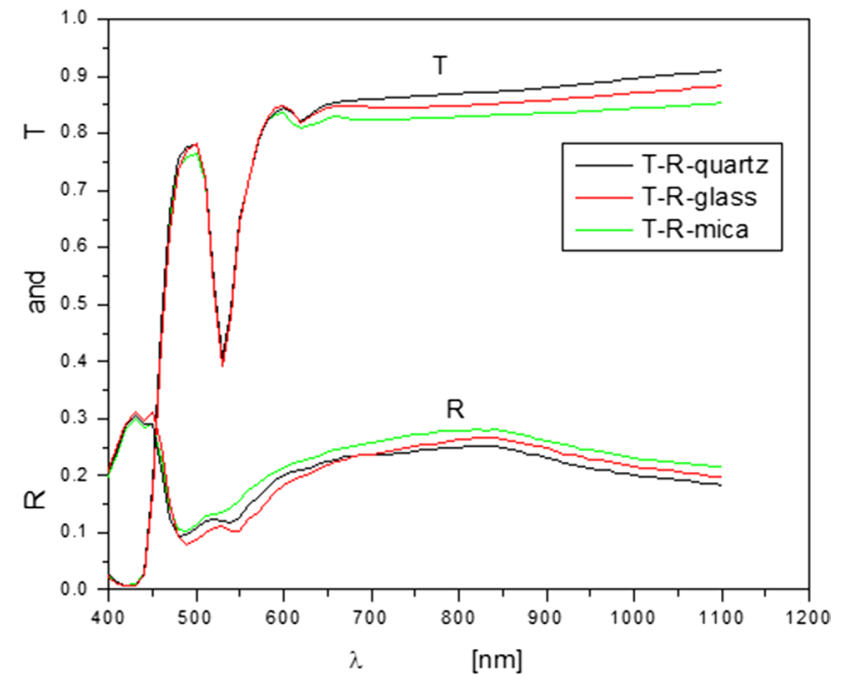

Fig. $2 T$ and $R$ versus $\lambda$ of NiTPP films on different substrates

the two edges which can be attributed to different band gap absorption processes (El-Denglawey 2018).

$E_{\mathrm{g}}^{\mathrm{opt}}$ can be classified into direct $E_{\mathrm{gd}}^{\mathrm{opt}}$ and indirect $E_{\mathrm{gi}}^{\mathrm{opt}}$ and can be calculated according to the available electronic transition (Tauc 1976: El-Denglawey 2018). The calculated values of $\alpha$ are more than $10^{4}(\mathrm{~cm})^{-1}$ which are included within high-absorption region. Figure 3 shows the $(\alpha h \nu)^{1 / 2}$ versus $(h \nu)$ of NiTPP films as a function of different substrates. It is obvious that films are characterized by two edges. The first one is $E_{\mathrm{gi}}^{\mathrm{opt}}$ and the other one represents the fundamental gap, $E_{\mathrm{g}}$, and the obtained data are summarized in Table 1. NiTPP films deposited on mica substrate have the minimum values of both $E_{\mathrm{gi}}^{\mathrm{opt}}$ and $E_{\mathrm{g}}$, and the maximum values are related to NiTPP films on quartz substrate, while NiTPP films on glass substrate have intermediate values, and similar phenomena were seen somewhere (Ma et al. 2017; Hasani et al. 2019).

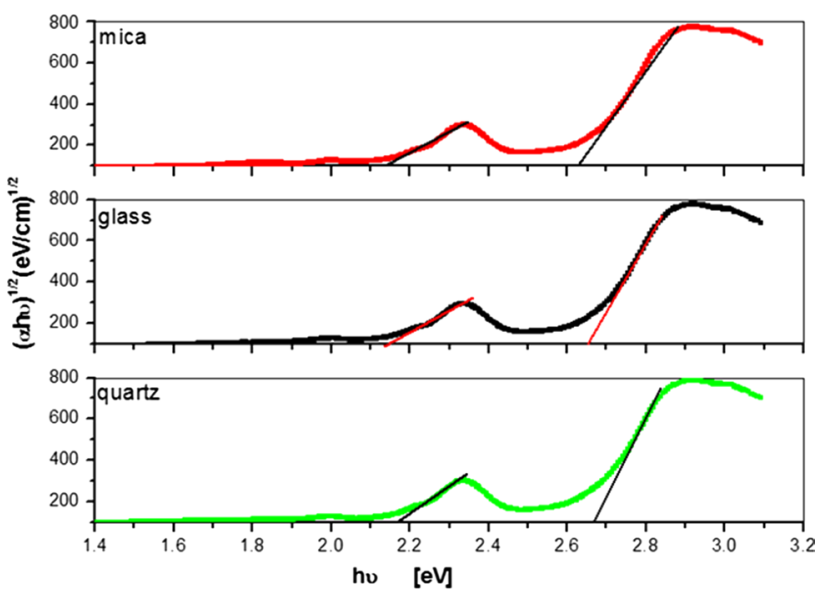

Fig. $3(\alpha h \nu)^{1 / 2}$ versus $(h \nu)$ of NiTPP films on different substrates 
Table 1 Optical constants of NiTPP films as a function of substrate type

\begin{tabular}{|c|c|c|c|c|c|c|c|c|c|c|c|}
\hline \multirow[t]{2}{*}{ Substrate type } & \multirow[t]{2}{*}{$\begin{array}{l}{[A]^{1 / 2} \times 10^{6}} \\
\left(\mathrm{~cm}^{-1} \mathrm{eV}^{-1}\right)^{1 / 2}\end{array}$} & \multirow[t]{2}{*}{$E_{\mathrm{gi}}^{\mathrm{opt}}(\mathrm{eV})$} & \multirow[t]{2}{*}{$E_{\mathrm{g}}^{\mathrm{opt}}(\mathrm{eV})$} & \multirow[t]{2}{*}{$\begin{array}{l}\mathrm{N} / \mathrm{m}^{*} \times 10^{56} \\
\left(\mathrm{~kg}^{-1} \mathrm{~m}^{-3}\right)\end{array}$} & \multirow[t]{2}{*}{$\varepsilon_{\mathrm{L}}$} & \multirow[t]{2}{*}{$n$} & \multirow[t]{2}{*}{$E_{\mathrm{o}}(\mathrm{eV})$} & \multirow[t]{2}{*}{$E_{\mathrm{d}}(\mathrm{eV})$} & \multirow[t]{2}{*}{$\varepsilon_{\infty}$} & \multicolumn{2}{|c|}{$\begin{array}{l}\text { Maximum at } \\
h \nu=2.9 \mathrm{eV}\end{array}$} \\
\hline & & & & & & & & & & $\varepsilon_{1}$ & $\varepsilon_{2}$ \\
\hline Mica & 4.1 & 2.00 & 2.57 & 1.12 & 3.7 & 1.92 & 4.10 & 5.89 & 2.28 & 8.6 & 3.77 \\
\hline Glass & 4.4 & 2.05 & 2.59 & 1.20 & 3.5 & 1.87 & 4.30 & 4.90 & 2.25 & 8.8 & 3.83 \\
\hline Quartz & 4.7 & 2.07 & 2.63 & 1.26 & 3.3 & 1.82 & 4.59 & 4.49 & 2.22 & 9.8 & 4.10 \\
\hline
\end{tabular}

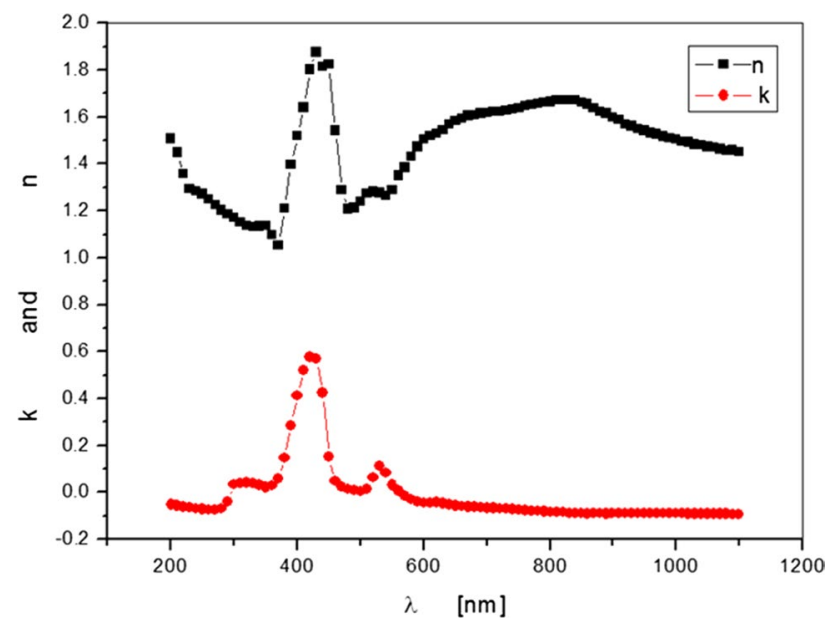

Fig. $4 k$ and $n$ of NiTPP films on glass substrate

As the deposition process was performed at room temperature and due to the presence of different thermal expansions between different substrates and NiTPP films, the deposited films contain high density of defects which introduce localized states as a tail through band gap (El-Denglawey 2018; Mott and Davis 1971; Tauc 1976), which determines the values of $E_{\mathrm{gi}}^{\mathrm{opt}}$. So, these explain the presence of amorphous phase of deposited films on different substrates.

Taking into account the obtained values of constant $A$, the higher the values of $A$, the lower the values of tails and consequently the higher the values of $E_{\mathrm{gi}}^{\mathrm{opt}}$, and the obtained values of constant $A$ support the XRD data and $E_{\mathrm{gi}}^{\mathrm{opt}}$ values (Mott and Davis 1971; El-Denglawey 2018).

Figure 4 shows the spectral dependence of $k$ and $n$ as a function of $\lambda$ for NiTPP films on quartz substrate. $n$ shows both anomalous dispersion at $\lambda \leq 800 \mathrm{~nm}$ and normal dispersion at $\lambda>800 \mathrm{~nm}$. $k$ and $n$ dependence shows a behavior similar to $T$ where two edges can be clearly observed at 435 and $500 \mathrm{~nm}$, respectively, which are, as mentioned previously, ascribed to different band gap absorption processes (El-Denglawey 2018; Tauc 1976).

At $\lambda>800, k$ decreases with the increase in $\lambda$ and tends to zero values. This can be ascribed to that the free carriers density at low energies decreases and tends to zero where

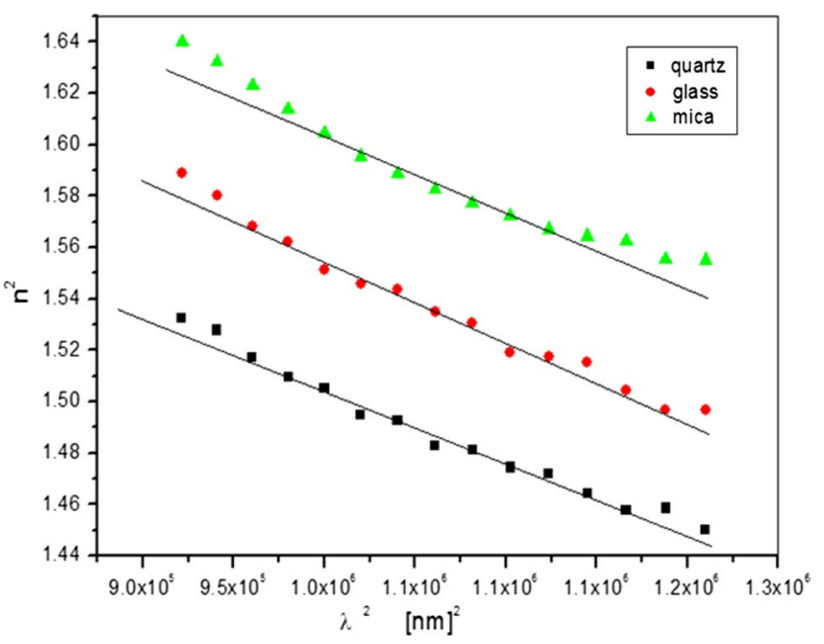

Fig. $5 n^{2}$ versus $\lambda^{2}$ of NiTPP films as a function of substrates type

NiTPP films are transparent at higher wavelength or nonabsorbing region because of unavailability of energy to release free electrons for electronic transitions.

To see how $\mathrm{N} / \mathrm{m}^{*}$ and $\varepsilon_{\mathrm{L}}$, of NiTPP affected by substrate type, $n^{2}$ as function of $\lambda^{2}$ is figured as shown in Fig. 5 according to (Wemple and DiDomenico 1970; ElDenglawey 2018). Table 1 summarizes the obtained values of $n, \mathrm{~N} / \mathrm{m}^{*}$ and $\varepsilon_{\mathrm{L}}$.

It can be observed that the slope of the straight line increases and consequently the values of $\mathrm{N} / \mathrm{m} *$ increase, $n$ and $\varepsilon_{\mathrm{L}}$ decrease from mica to quartz substrate. The decrease in $\mathrm{n}$ may attribute to film density change (Bakr et al. 2003). At $\lambda>800 \mathrm{~nm}$, NiTPP films become transparent and nonabsorbing, so single-oscillator model can be used to analyze n (Wemple and DiDomenico 1970; El-Denglawey 2018), and $E_{\mathrm{d}}, E_{\mathrm{o}}$ and $\varepsilon_{\infty}$ can be calculated according to the procedure mentioned in El-Denglawey (2011) by plotting $\left(n^{2}(h \nu)\right.$ $-1)^{-1}$ versus $(h \nu)^{2}$ of NiTPP films as a function of substrate type using slope and intercept $\left((h \nu)^{2}=0\right)$ in Fig. 6, and the obtained values are included in Table 1. One can recognize that $E_{\mathrm{d}}$ and $E_{\mathrm{o}}$ had a contradicted behavior, and the increase in $E_{\mathrm{o}}$ is related to $E_{\mathrm{gi}}^{\mathrm{opt}}$ according to Tanaka (1980) and ElNahass et al. (2005) which depends on localized states, so $E_{\mathrm{o}}$ and $E_{\mathrm{gi}}^{\mathrm{opt}}$ had a similar behavior. 


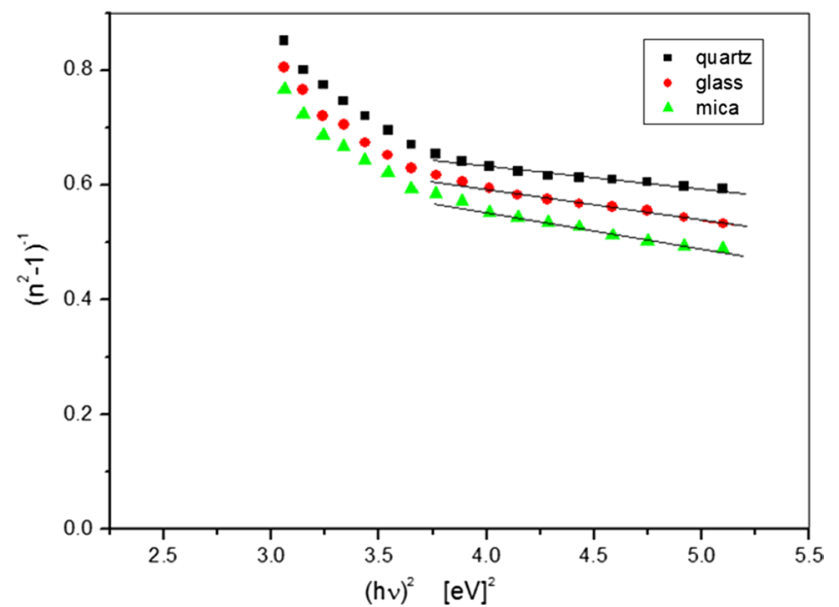

Fig. $6\left(n^{2}-1\right)^{-1}$ versus $(h \nu)^{2}$ of NiTPP films as a function of substrates type

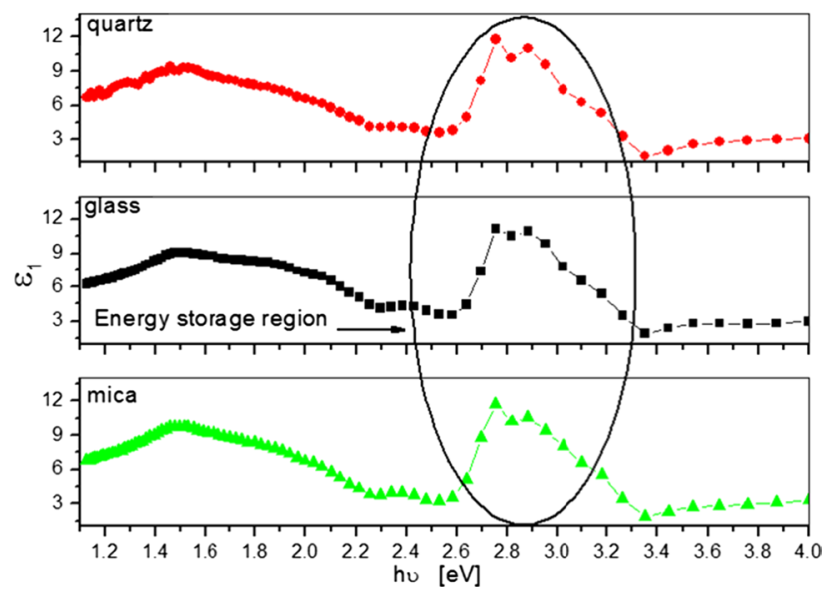

Fig. $7 \varepsilon_{1}$ versus $(h \nu)$ of NiTPP films as a function of substrates type

The calculated value of $\beta(0.379)$ reveals that NiTPP is a covalent compound as organic semiconductors (Chopra 2013). More information is available in El-Denglawey (2011). Free carrier concentration plays an important role of values of difference in $\varepsilon_{\infty}$ and $\varepsilon_{\mathrm{L}}$ (El-Nahass et al. 2005, 2011). Similar behavior was observed in Li et al. (2010) and Rozati et al. (2009).

It was reported that materials with high dielectric properties and low loss factor are preferred for high energy storage density devices, optoelectronic devices and dielectric applications (Zhang et al. 2016; Vidya and Thomas 2018). According to this viewpoint, it is interesting to study dielectric properties of NiTPP films as a function of substrate type. Materials' electronic structure can be inferred by light reflection, loss and propagation through material. Figures 7 and 8 show $\varepsilon_{1}$ and $\varepsilon_{2}$ of NiTPP films as a function of substrate type. Two edges near both $E_{\mathrm{gi}}^{\mathrm{opt}}$ and $E_{\mathrm{g}}$ and two dielectric

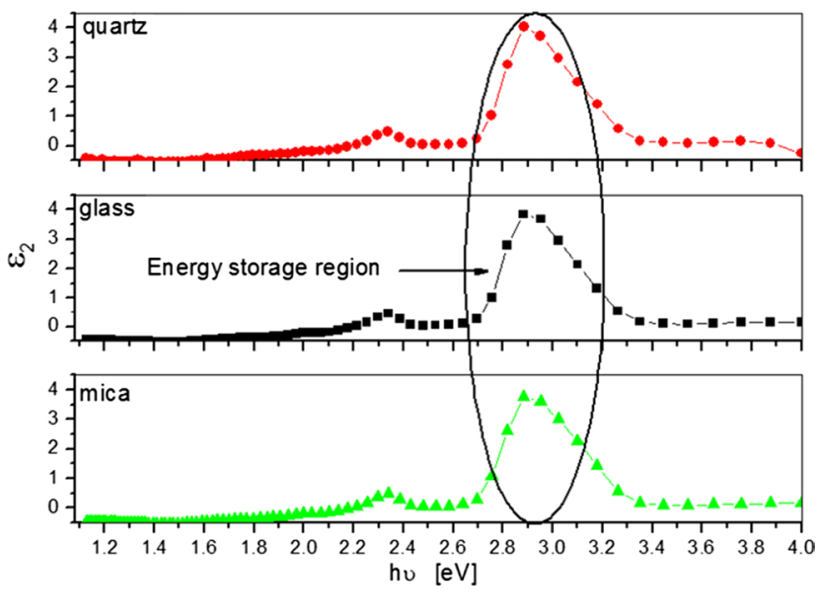

Fig. $8 \varepsilon_{2}$ versus $(h \nu)$ of NiTPP films as a function of substrates type

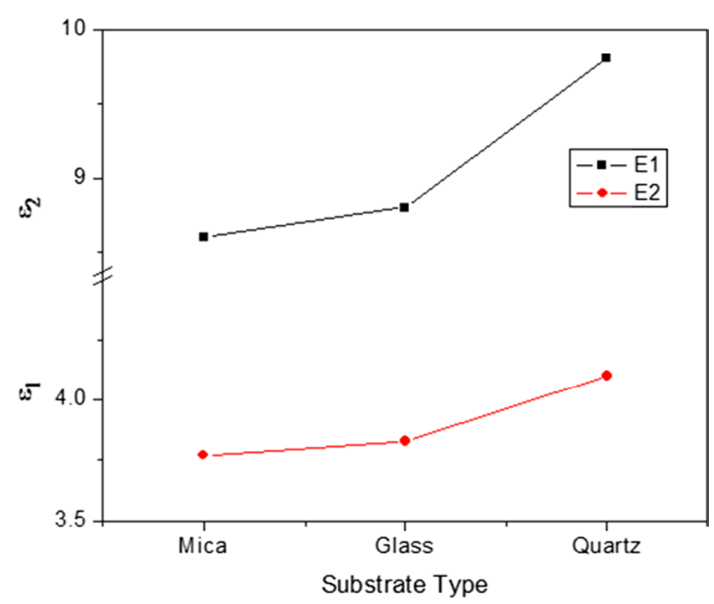

Fig. 9 Values of $\varepsilon_{1}$ and $\varepsilon_{2}$ at $h \nu=2.9 \mathrm{eV}$

maximums could be observed which inferred the probability of dielectric applications of NiTPP films. According to Zhang et al. (2016), the released maximums of $\varepsilon_{1}$ and $\varepsilon_{2}$ within the energy range of $2.5-3.5 \mathrm{eV}$ as depicted in Figs. 7 and 8 show the energy storage region where energy can be stored. Such issue gives a spotlight of energy storage applications of NiTPP films. Values of $\varepsilon_{1}$ and $\varepsilon_{2}$ were obtained at $h \nu=2.9 \mathrm{eV}$ and are depicted in Fig. 9 and included in Table 1, and it increases with the following sequences: mica $<$ glass $<$ quartz and consequently the energy storage increases as well.

\section{Conclusion}

This article focuses on the properties of NiTPP films, it is affected by different substrate types for energy storage applications. NiTPP films were deposited on mica, glass and quartz substrates by thermal evaporation technique. 
Structural properties show that all films have nanostructure property with the crystallite sizes of 8,10 and $11 \mathrm{~nm}$ for mica, glass and quartz, respectively, which confirm the structural enhancement and more ordering in the mentioned sequence of substrates. High values of transmission were obtained as well as high absorption coefficient, two gaps, namely optical and fundamental gaps, were calculated for NiTPP films on mica, glass and quartz substrates, and the highest values were obtained for NiTPP films on quartz substrates which are $91 \%, 2 \times 10^{6}\left(\mathrm{~cm}^{-1}\right), 2.07$ and $2.63 \mathrm{eV}$, respectively. The dependence of $\varepsilon_{1}$ and $\varepsilon_{2}$ on photon energy as a function of substrate type shows energy storage regions increase in mica, glass and quartz sequence. The dependence of NiTPP films on substrate type gives high values of $T, \alpha$, $E_{\mathrm{gin}}^{\mathrm{opt}}, E_{\mathrm{g}}^{\mathrm{opt}}$ and the two maximums of $\varepsilon_{1}$ and $\varepsilon_{2}$ within the energy range of $2.5-3.5 \mathrm{eV}$ which are used for energy storage applications.

Acknowledgements This work was supported by the vice presidency of Graduate Studies and Academic Research (Taif University, KSA), Research Group ID: 1-440-6142. It is gratefully acknowledged.

\section{Compliance with ethical standards}

Ethical approval This article does not contain any studies with human participants or animals performed by any of the authors.

\section{References}

Al-Kuhaili MF (2019) Enhancement of plasmonic transmittance of porous gold thin films via gold metal oxide bi-layers for solar energy-saving applications. Sol Energy 181:456-463

Alptekin O, Sen B, Savk A, Ercetin U, Mustafov SD, Fellah MF, Sen F (2020) Use of silica-based homogeneously distributed gold nickel nanohybrid as a stable nanocatalyst for the hydrogen production from the dimethylamine borane. Sci Rep 10:7215. https://doi. org/10.1038/s41598-020-64221-y

Bakr NA, El-Hadidy H, Hammam M, Migahed MD (2003) Refractive index, extinction coefficient and DC conductivity of amorphous arsenic triselenide thin film doped with silver. Thin Solid Films 424:296-302

Bode S, Hapke J, Zisler S (2003) Need and options for a regenerative energy supply in holiday facilities. Tour Manag 24:257-266

Chen Z, Gao P, Wang W, Klyatskaya S, Karger ZZ, Wang D, Kübel C, Fuhr O, Fichtner M, Ruben M (2019) A Lithium-Free Energy Storage Device based on an Alkyne-Substituted-Porphyrin Complex. Sus. Chem, Chem. https://doi.org/10.1002/cssc.201901541

Chopra KN (2013) A short note on the organic semiconductors and their technical applications in Spintronics. Lat Am J Phys Educ 7:674-680

Cuce E, Harjunowibowo D, Cuce PM (2016) Renewable and sustainable energy saving strategies for greenhouse systems: a comprehensive review. Renew Sustain Energy Rev 64:34-59

Dongol M, Abou Zied M, Gamal GA, El-Denglawey A (2004) The effects of composition and heat treatment on the structural and optical properties of $\mathrm{Ge}_{15} \mathrm{Te}_{85-\mathrm{x}} \mathrm{Cu}_{\mathrm{x}}$ thin films. Phys $\mathrm{B}$ 353:169-175
Dongol M, El-Denglawey A, Abd El Sadek MS, Yahia IS (2015) Thermal annealing effect on the structural and the optical properties of Nano CdTe films. Optik 126:1352-1357

Dongol M, El-Denglawey A, Elhady AF, Ebied MS (2016) Synthesis and the RDF fine structure of $\mathrm{Ge}_{0.15} \mathrm{Te}_{0.78} \mathrm{Cu}_{0.07}$ bulk alloy. Optik 127:8186-8193

El-Denglawey A (2011) Characterization of As-Se-Tl films near infrared region. J Non-Cryst Solids 357:1757-1763

El-Denglawey A (2018) Illumination effect on the structural and optical properties of nano meso nickel (II) tetraphenyl-21H, 23H-porphyrin films induces new two hours photo bleached optical sensor. J Lumin 194:381-386

El-Denglawey A, Makhlouf MM, Dongol M, El-Nahass MM (2015) The effect of long term aging on the structural and optical properties of nano metallo-tetraphenyl porphine films. J Mater Sci: Mater Electron 26:5603-5609

El-Denglawey A, Makhlouf MM, Dongol M (2016) Physical aging effects on the structural and optical properties of nano As-Se-Tl films. J Non-Cryst Solids 449:34-40

El-Nahass MM, Dongol M, Abou-zied M, El-Denglawey A (2005) The compositional dependence of the structural and optical properties of amorphous $\mathrm{As}_{20} \mathrm{Se}_{80-\mathrm{x}} \mathrm{Tl}_{\mathrm{x}}$ films. Phys B 368:179-187

El-Nahass MM, Ammar AH, Farag AAM, Atta AA, El-Zaidia EFM (2011) Effect of heat treatment on morphological, structural and optical properties of CoMTPP thin films. Solid State Sci 13:596-600

El-Nahass MM, Soliman HS, El-Denglawey A (2016) Absorption edge shift, optical conductivity, and energy loss function of nano thermal-evaporated $\mathrm{N}$ - type anatase $\mathrm{TiO}_{2}$ films. Appl Phys A 122:775-786

Favoino F, Overend M, Jin Q (2015) The optimal thermo-optical properties and energy saving potential of adaptive glazing technologies. Appl Energy 156:1-15

Gao P, Chen Z, Karger ZZ, Mueller JE, Jung C, Klyatskaya S, Diemant T, Fuhr O, Jacob T, Behm RJ, Ruben M, Fichtner M (2017) Porphyrin complex as self-conditioned electrode material for high performance energy storage. Angew Chem Int Ed. https://doi. org/10.1002/anie.201702805

Hasani E, Kamalian M, Arashti MG, Habashi LB (2019) Effect of substrate properties on nanostructure and optical properties of CdTe thin films. J Electron Mater 48:4283-4292

He X, Xiao G, Hu B, Tan L, Tang H, He S, He Z (2020) The applications of energy regeneration and conversion technologies based on hydraulic transmission systems: a review. Energy Convers Manag 205:112413

Kabir MH, Ali MM, Kaiyum M, Rahman MS (2019) Effect of annealing temperature on structural morphological and optical properties of spray pyrolized Al-doped ZnO thin films. J Phys Commun 3:105007

Karger ZZ, Gao P, Ebert T, Klyatskaya S, Chen Z, Ruben M, Fichtner M (2019) New organic electrode materials for ultrafast electrochemical energy storage. Adv Mater 31:1806599

Kumar NA, Gaddam RR, Suresh M, Varanasi SR, Yang D, Bhatia SK, Zhao XS (2017) Porphyrin-graphene oxide frameworks for long life sodium ion batteries. J Mater Chem A 5:13204-13211

Li Y, Xu L, Li X, Shen X, Wang A (2010) Effect of aging time on the structural and optical properties of $\mathrm{ZnO}$ thin films prepared by sol-gel method. Appl Surf Sci 256:4543-4547

Ma L, Ai X, Wu X (2017) Effect of substrate and Zn doping on the structural, optical and electrical properties of CdS thin films prepared by CBD method. J Alloys Compd 691:399-406

Makhlouf MM, El-Denglawey A, Zeyada HM, El-Nahass M (2014) The structural and optical characterizations of tetraphenyl porphyrin thin films. J Lumin 147:202-208

Mott NF, Davis E (1971) Electronic processes in non-crystalline materials. Oxford University Press, Oxford 
Ngamsinlapasathian S, Kitiyanan A, Fujieda T, Yoshikawa S (2006) Effect of substrates on dye-sensitized solar cell performance using nanocrystalline $\mathrm{TiO}_{2} \mathrm{~S}$. ECS Trans 1:7-15

Osuwa JC, Chigbo NI (2012) Characterization of structural and electrical properties of electro-deposited cadmium telluride (CdTe) thin films at varying deposition time on glass FTO. Chalcogenide Lett 9:501-508

Ratniyomchai T, Kulworawanichpong T (2017) A demonstration project for installation of battery energy storage system in mass rapid transit. Energy Procedia 138:93-98

Rozati SM, Moradi S, Golshahi S, Martins R, Fortunato E (2009) Electrical, structural and optical properties of fluorine-doped zinc oxide thin films: effect of the solution aging time. Thin Solid Films 518:1279-1282

Said MA, Hassan H (2018) Effect of using nano particles on the performance of thermal energy storage of phase change material coupled with air-conditioning unit. Energy Convers Manag 171:903-916

Sen B, Kuzu S, Demir E, Yıldırır E, Sen F (2017) Highly efficient catalytic dehydrogenation of dimethyl ammonia borane via monodisperse palladium-nickel alloy nanoparticles assembled on PEDOT. International J Hydrogen Energy. https://doi.org/10.1016/j.ijhyd ene.2017.05.115

Singh D, Kumar S, Thangaraj R (2014) Effect of different substrate on optical properties of $\mathrm{Se}_{92} \mathrm{Te}_{4} \mathrm{Ag}_{4}$ films. Phase Transit 87:1-10

Soliman HS, Saadeldin MM, Sawaby K, Eldenglawey A (2015) Properties of nano and micro p-type $\mathrm{Cu}_{2}$ s films. CJPAS 9:3247-3257

Steffen B, Egli F, Pahle M, Schmidt TS (2020) Navigating the clean energy transition in the COVID-19. Crisis. https://doi. org/10.1016/j.joule.2020.04.011

Sugiyama M, Fujii K, Nakamura S (2016) Solar to chemical energy conversion: Theory and application. Springer, Cham

Tanaka K (1980) Optical properties and photoinduced changes in amorphous As-S Films. Thin Solid Films 66:271-279
Tauc J (1976) Amorphous and liquid semiconductors. Plenum, New York

Vidya S, Thomas JK (2018) Optical and dielectric investigations of nano crystalline scheelite $\mathrm{A}_{0.5} \mathrm{~B}_{0.5} \mathrm{MoO}_{4}(\mathrm{~A}=\mathrm{B}=\mathrm{Ba}, \mathrm{Sr}$ and $\mathrm{Ca})$. Bull Pure Appl Sci 37:26-34

Warren C, Becken S (2017) Saving energy and water in tourist accommodation: a systematic literature review (1987-2015). Int J Tour Res 19:289-303

Wemple SH, DiDomenico MD (1970) Behavior of the electronic dielectric constant in covalent and ionic materials. Phys Rev B 3:1338-1352

Wengenmayr R, Bührke T (2013) Renewable Energy, 2nd edn. WILEYVCH Verlag GmbH \& Co., KGaA, Weinheim

Williamson JK, Hall W (1953) X-ray line broadening from filed aluminum and wolfram. Acta Metall 1:22-31

Xu B, Qi S, Jin M, Cai X, Lai L, Sun Z, Han X, Lin Z, Shao H, Peng P, Xiang Z, Elshof JE, Tan R, Liu C, Zhang Z, Duan X, Ma J (2019) 2020 roadmap on two-dimensional materials for energy storage and conversion. Chin Chem Lett. https://doi.org/10.1016/j.cclet .2019 .10 .028

Zhang TF, Tang XG, Liu QX, Jiang YP, Jiang LL, Luo L (2016) Optical and dielectric properties of $\mathrm{PbZrO}_{3}$ thin films prepared by a sol-gel process for energy-storage application. Mater Des 90:410-415

Zhang X, Zhao G, Zhou J, Lin X, Zhang T, Duan G, Wang J, Han G (2018) APCVD prepared $\mathrm{TiN}_{\mathrm{x}} \mathrm{O}_{\mathrm{y}}$ films with energy-saving and self-cleaning Functions. J Alloys Compd 746:445-452

Zheng H, Wei A, Xiong H (2018) Influence of deposition parameters on the morphology, structural and optical properties of $\mathrm{Cu}_{2} \mathrm{ZnSnS}_{4}$ thin films grown by solvothermal method. Chalcogenide Lett 15:327-337 